\title{
PREOPERATIVE COMPUTED TOMOGRAPHY VOLUMETRY AND GRAFT WEIGHT ESTIMATION IN ADULT LIVING DONOR LIVER TRANSPLANTATION
}

Estimativa do peso do enxerto hepático no transplante intervivos através da volumetria realizada por tomografia computadorizada pré-operatória

Rafael S. PINHEIRO ${ }^{1}$,Ruy J. CRUZ-JR ${ }^{1}$, Wellington ANDRAUS1, Liliana DUCATTI ${ }^{1}$,

Rodrigo B. MARTINO'1, Lucas S. NACIF' ${ }^{1}$ Vinicius ROCHA-SANTOS ${ }^{1}$, Rubens M ARANTES ${ }^{1}$,

Quirino LAI $^{2}$, Felicia S. IBUKI ${ }^{3}$, Manoel S. ROCHA ${ }^{3}$, Luiz A. C. D’ALBUQUERQUE ${ }^{1}$

From the 'Divisão de Transplante de Órgãos do Aparelho Digestivo, Departamento de Gastroenterologia, Faculdade de Medicina Universidade de São Paulo, São Paulo, Brasil; 2Divisão de Transplante, Departamento de Cirurgia, Universidade de L'Aquila; San Salvatore Hospital, Itália; ${ }^{3}$ Departamento de Radiologia, Faculdade de Medicina, Universidade de São Paulo, São Paulo, Brasil ('Digestive Organ Transplantation Division, Department of Gastroenterology, Faculty of Medicine, University of São Paulo, São Paulo, SP, Brazil; ${ }^{2}$ Transplantation Division, Department of Surgery, University of L'Aquila; San Salvatore Hospital, Italy; ${ }^{3}$ Department of Radiology, Faculty of Medicine, University of São Paulo, São Pauloi, SP, Brazil.

HEADINGS - Liver transplantation. Living donors. Multidetector Computed Tomography.
ABSTRACT - Background: Computed tomography volumetry (CTV) is a useful tool for predicting graft weights (GW) for living donor liver transplantation (LDLT). Few studies have examined the correlation between CTV and GW in normal liver parenchyma. Aim: To analyze the correlation between CTV and GW in an adult LDLT population and provide a systematic review of the existing mathematical models to calculate partial liver graft weight. Methods: Between January 2009 and January 2013, 28 consecutive donors undergoing right hepatectomy for LDLT were retrospectively reviewed. All grafts were perfused with HTK solution. Estimated graft volume was estimated by CTV and these values were compared to the actual graft weight, which was measured after liver harvesting and perfusion. Results: Median actual GW was $782.5 \mathrm{~g}$, averaged $791.43 \pm 136 \mathrm{~g}$ and ranged from $520-1185 \mathrm{~g}$. Median estimated graft volume was $927.5 \mathrm{ml}$, averaged $944.86 \pm 200.74 \mathrm{ml}$ and ranged from 600-1477 ml. Linear regression of estimated graft volume and actual GW was significantly linear ( $G W=0.82$ estimated graft volume, $r^{2}=0.98$, slope $=0.47$, standard deviation of 0.024 and $\left.p<0.0001\right)$. Spearman Linear correlation was 0.65 with $95 \% \mathrm{Cl}$ of $0.45-0.99$ ( $p<0.0001)$. Conclusion: The one-to-one rule did not applied in patients with normal liver parenchyma. A better estimation of graft weight could be reached by multiplying estimated graft volume by 0.82 .

\section{Correspondência:}

Rafael S. Pinheiro,

E-mail: rsnpinheiro@gmail.com

Fonte de financiamento: não há

Conflito de interesse: não há.

Recebido para publicação:

Aceito para publicação:

\section{DESCRITORES - Transplante de} fígado. Doadores vivos. Tomografia Computadorizada Multidetectores.
RESUMO - Racional: A volumetria por tomografia computadorizada (VTC) é uma ferramenta útil para a previsão do peso do enxerto (PE) para o transplante hepático com doador vivo (TFDV). Poucos estudos examinaram a correlação entre o VTC e PE no parênquima hepático normal. Objetivo: Analisar a correlação entre VTC e PE em uma população adulta de doadores para o TFDV e realização de revisão sistemática dos modelos matemáticos existentes para calcular o peso de enxertos hepáticos parciais. Métodos: Foram revisados retrospectivamente 28 doadores consecutivos submetidos à hepatectomia direita para o TFDV entre janeiro de 2009 a janeiro de 2013. Todos os doadores eram adultos saudáveis com VTC pré-operatório. Os enxertos foram perfundidos com solução de preservação HTK. O volume estimado foi obtido por VTC e estes valores foram comparados com o peso real do enxerto, o qual foi aferido depois da hepatectomia e perfusão do enxerto. Resultados: A mediana do PE real foi de 782,5 g, média de $791,43 \pm 136 \mathrm{~g}$, variando de 520-1185 g. A mediana do volume estimado do enxerto foi de 927,5 $\mathrm{ml}$, média de $944,86 \pm 200,74 \mathrm{ml}$ e variou de $600-1477 \mathrm{ml}$. A regressão linear volume estimado do enxerto e $P E$ real foi significativamente linear $(P E=0.82$ do volume estimado do enxerto, $r 2=0,98$, declive=0,47, desvio-padrão de 0,024 e p<0,0001). Correlação linear de Spearman foi de 0,65, com IC de 95\% do 0,45-0,99 ( $p<0,0001)$. Conclusão: A regra de "um-para-um" não deve ser empregada em pacientes com parênquima hepático normal. A melhor estimativa do peso do enxerto hepático de doador vivo pode ser alcançado através da multiplicação do VTC por 0,82.

INTRODUCTION

(cc) BY This is an open-access article distributed under the terms of the Creative Commons Attribution License.
Che first living donor liver transplantation (LDLT) was performed in 1989 at our Institution ${ }^{15}$. Since then, surgical techniques and patient's care improvements have established LDLT as a valid option of overcoming the shortage of deceased donors.

Initially, LDLT was exclusive to pediatric patients, although over time it also became good option to adult recipients as well. One of the major concerns of this procedure is to provide an adequate graft volume while preserving a suitable hepatic remnant for the donor. Reduced grafts are associated with small for size syndrome and poor outcomes. In this particular setting, preoperative radiological evaluation of liver volume is the standard method for donor evaluation, aiming minimization of unnecessary risks.

Therefore, accurate assessment of the volume of the liver and its lobes prior to surgery is mandatory. Computed tomography volumetry (CTV) is a useful tool for predicting graft weights $(G W)$ for $\operatorname{LDLT}^{16,18}$. However, for the conversion of volumetric weight, the rule of "one-to-one" does not offer good results due that this rule was based in the 
weight using cirrhotic livers ${ }^{20}$. Fw studies have examined the correlation between CTV and GW in normal liver parenchyma.

The aim of this paper was to analyze the correlation between CTV and GW in an adult LDLT population, and also provide a systematic review of the existing mathematical models to calculate partial liver graft weight or volume, based on different radiological parameters.

\section{METHODS}

Between January 2009 and January 2013, 28 consecutive donors undergoing right hepatectomy for LDLT were retrospectively reviewed. All donors were healthy adults with preoperative CTV.

Hepatectomy cutting plane was guided by ischemic line after a short period (about $2 \mathrm{~min}$ ) of right pedicle clamping (i.e. right hepatic artery and right portal vein). Right hepatic graft, including middle hepatic vein, was used in all but two cases. Grafts were perfused via the right portal vein with cold histidine-tryptophan-ketoglutarate (HTK) solution as soon as hepatectomy was completed. The solution was drained from the liver and a pre-calibrated digital scale was used to define the actual GW.

\section{Preoperative measurement of the liver volume}

Multidetector computed tomography (CT) images were obtained with four different devices: CT Discovery 750 HD (GE Medical Systems, Milwaukee, Wisconsin, USA), CT Light Speed (GE Medical Systems, Milwaukee, Wisconsin, USA), CT IDT MX8000 (Philips Healthcare, Cleveland, Ohio, USA) and CT Brilhance 64 (Philips Healthcare, Cleveland, Ohio, USA), with a 1-mm slice thickness and $70 \mathrm{~s}$ after the intravenous administration of iodine contrast media (portal venous phase). These data were used for $\mathrm{CT}$ volumetry measurements. The scanning parameters were as follows: $120 \mathrm{kV}$ and $\mathrm{mAs}$ appropriate to body habitus.

The right lobe graft volume (GV) was measured by tracing a line on the right of the middle hepatic vein, thus defining the virtual hepatectomy plan. The perimeters of the liver and the graft were outlined by hand tracing on each slice by an abdominal radiologist. The enclosed area was calculated with image analysis software Volume Viewer (GE Medical Systems, Milwaukee, Wisconsin, USA). The liver volume (in milliliters) was then obtained as the sum of all areas from the intervals of the serial CT slices (Figure 1).
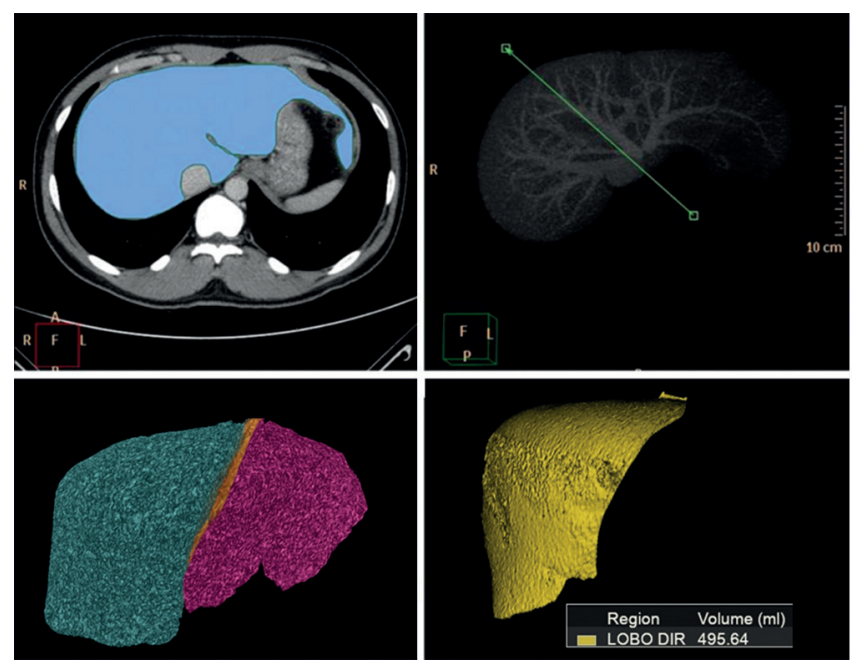

FIGURE 1-Images from pre operative CT hepatic graft volumetry of living donor: A) delimitation of whole hepatic area for CT volumetry; B) green line demarking medium hepatic vein, this line splits right and left hepatic lobes; C) right and left hepatic lobes; D) virtual right hepatectomy with estimated volume
Estimated graft volume (EGV) was obtained by CTV, and these values were compared to the actual GW (AGW), which was defined after liver harvesting and perfusion.

\section{Statistical analysis}

Values are shown as mean \pm standard deviation. Statistical analysis was performed using R version 2.15.2 (The R Foudantion for Statistical Computing). A value of $p<0.05$ was considered significant. Relation between estimated GV and AGW was determined by use of linear regression analysis; furthermore, linear correlation of Spearman and its 95\% confidence interval were presented.

\section{RESULTS}

The donor's demographics and perioperative parameters are summarized in Table 1. Blood products transfusion was not necessary in any of the donor's surgeries.

TABLE 1 - Donor's characteristics: continuous variables are reported as medians and ranges; categorical variables are reported as numbers and percentages.

\begin{tabular}{|l|c|}
\hline Variables & Data \\
\hline Age (years) & $29(17-43)$ \\
\hline Male gender (\%) & $21(75)$ \\
\hline Max postoperative total bilirrubine $(\mathrm{mg} / \mathrm{dl})$ & $2.74(1.38-5.62)$ \\
\hline Whole liver CTV $(\mathrm{ml})$ & $1493.5(1106-2052)$ \\
\hline BMI & $23.74(20.42-29.12)$ \\
\hline
\end{tabular}

Median graft versus recipient weight ratio was $1.12 \%$, and ranged from 0.81 to $1.45 \%$. Recipient's estimated standard liver volume ranged from 948 to $1471 \mathrm{~g}$ (median 1277g). The median relation between GW and estimated standard liver volume was 62.45 (44.23-80.57).

Median actual GW was $782.5 \mathrm{~g}$, averaged $791.43 \pm 136$ $\mathrm{g}$, and ranged from 520 to $1185 \mathrm{~g}$. Median estimated GV was $927.5 \mathrm{ml}$, averaged $944.86 \pm 200.74 \mathrm{ml}$, and ranged from 600 to $1477 \mathrm{ml}$. Linear regression of estimated GV and actual GW were significantly linear $(A G W=0.82 E G V, r 2=0.98$, slope $=0.47$, standard deviation of 0.024 and $p<0.0001$ ) as illustrated in Figure 2. Spearman linear correlation was 0.65 with $95 \% \mathrm{Cl}$ of $0.45-0.99(p<0.0001)$.

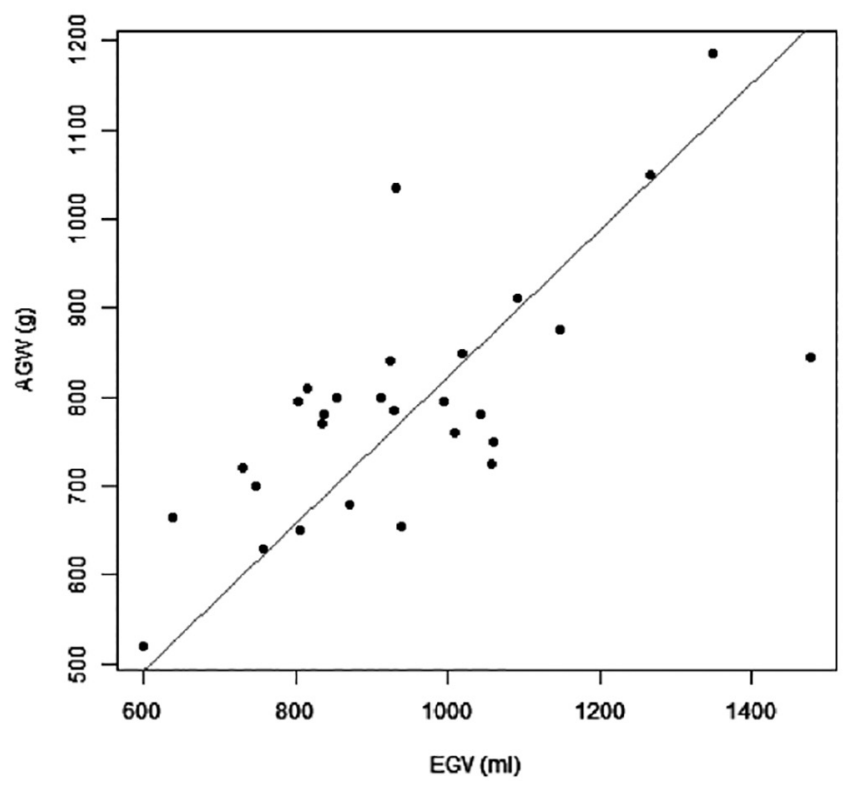

FIGURE 2 - Positive linear correlation between estimated graft volume (EGV) and actual graft weight (AGW) 
TABLE 2 - Studies evaluating right graft volume or weight estimation.

\begin{tabular}{|c|c|c|c|c|c|c|}
\hline Author ref & Year & Country & Formula & Patients enrolled & Type of graft & Solution \\
\hline Hwang et al. ${ }^{6}$ & 2002 & Korea & $\mathrm{GW}=\mathrm{EGV} / 1.22$ & 12 & Right lobe & HTK \\
\hline Gondolesi et al. ${ }^{4}$ & 2004 & USA & $R G V=440 \times B S A$ & 91 & Right lobe & UW \\
\hline Lemke et al..$^{12}$ & 2006 & Germany & $R G W=(0.678 \times E G V)+143.704$ & 16 & Right lobe & HTK \\
\hline Khalaf et al. ${ }^{8}$ & 2007 & Saudi Arabia & $R G V=E G V \times S L V$ & $\begin{array}{c}28 \\
3\end{array}$ & $\begin{array}{l}\text { Right lobe } \\
\text { Extended right lobe§ }\end{array}$ & - \\
\hline Kayashima et al. ${ }^{7}$ & 2008 & Japan & $\begin{array}{c}\mathrm{GV}=70.767+[0.703 \times \mathrm{EGV}]+(1.298 \times \\
\text { donor age })\end{array}$ & $\begin{array}{c}139 \\
77\end{array}$ & $\begin{array}{l}\text { Left lobe } \\
\text { Right lobe* }\end{array}$ & UW \\
\hline Kim et al. ${ }^{9}$ & 2010 & Korea & 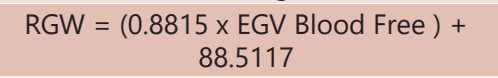 & 88 & Right lobe & HTK \\
\hline Chan et al. ${ }^{2,3}$ & 2011 & China & $R G W=E G V / 1.19$ & 285 & Extended right lobe§ & HTK \\
\hline Lee et al. ${ }^{11}$ & 2011 & Taiwan & $R G V=\left[R^{2} /\left(R^{2}+L^{2}\right)\right] \times 100 \%$ & 4 & Full right (split) & HTK \\
\hline Wang et al. ${ }^{21}$ & 2011 & Taiwan & $R G V=S L V x\left[R^{2} /\left(R^{2}+L^{2}\right)\right]$ & 175 & Right lobe & HTK \\
\hline Yoneyama et al. ${ }^{22}$ & 2011 & Japan & $R G W=0.84 \times E G V$ & 39 & Right lobe & HTK/UW \\
\hline Tongyoo et al. ${ }^{18}$ & 2012 & USA & $\begin{aligned} R G V=S L V \times & {\left[\left(R A^{2}+R P^{2}\right) /\right.} \\
& \left.\left(R A^{2}+R P^{2}+L^{2}\right)\right]\end{aligned}$ & 200 & Right lobe & HTK \\
\hline Present study & 2014 & Brazil & $\mathrm{RGW}=0.82 \times \mathrm{EGV}$ & 28 & Right lobe & HTK \\
\hline
\end{tabular}

* including right lobes, extended right lobe and 1 posterior segment.; § including medium hepatic vein. Abbreviation: BSA =body surface area, calculated by Mostellerxxxx formula: square root (weight $[\mathrm{Kg}]$ x height $[\mathrm{cm}] / 3600$ ); $E G V=$ estimated graft volume by $C T$ volumetry; $G V=$ graft volume; $G W=$ graft weight; $L=l$ eft portal; vein diameter; $\mathrm{R}=$ right portal vein diameter; $\mathrm{RA}=$ right anterior portal vein diameter; $\mathrm{RP}=$ right posterior portal vein diameter; $\mathrm{RGV}=$ right graft volume ; $\mathrm{RG}=$ right $\mathrm{graft}$ weight; $\mathrm{SLV}=$ stand liver volume calculated by Makuuchixxx formula $(706.2 \mathrm{x}$ body surface area [m2] +2.4$)$.

\section{DISCUSSION}

An accurate preoperative GV estimation is essential in selecting suitable donors for adequate recipients of LDTL. It can provide valuable information to keep a safe remnant liver volume to the donor as well as reducing the recipient's postoperative morbidity and mortality.

LDTL recipients should receive sufficient hepatic parenchyma. Ideally relationship between weight of the graft and weight of the recipient should be about $0.8-1 \%$ to avoid small for size syndrome ${ }^{1,10}$. Several studies have shown that weight of the graft and weight of the recipient ratio below 0.8 are associated with higher initial postoperative mortality (3-months survival of $54 \%)^{10}$. Other factors, such as portal venous pressure over $15 \mathrm{mmHg}{ }^{13}$ and excessive portal vein inflow (over than $250 \mathrm{ml} / \mathrm{min} / 100 \mathrm{~g}$ of liver weight) ${ }^{8}$ are also associate with poor outcomes.

Therefore, predicting actual graft weight with preoperative radiological evaluation is essential to define if LDLT is feasible. CTV is widely used as the standard method for preoperative estimation of hepatic graft weight ${ }^{9}$. However, it has been shown that CTV tends to overestimate both graft volume and weight ${ }^{12}$. Another concern is about health liver density; usually hepatic parenchyma volumetric measurements are compared based on the assumption that density is 1.00 $\mathrm{g} / \mathrm{ml}$. However, the relation between graft volume and GW is not exact and the one-to-one rule should not be applied for all patients. Yoneyama et al. ${ }^{22}$ have found correlation coefficients between estimated GV and GW in right lobe grafts of 0.84 and left lobe of $0.85^{22}$. They have emphasized that it could not be applicable in others institutions due to several biases.

Several factors can interfere in graft weight analysis, such as: 1) the hepatic transection line defined by ischemic area, and/or anatomical parameters; and 2) the timing to graft weight, since high osmotic preservation solutions can induce cellular dehydration causing significant weight reduction in liver grafts ${ }^{5,7}$. Recently, Satou et al. ${ }^{17}$ have shown a reduction of up to $10 \%$ of the initial weight post-hepatectomy after back-table surgery has been completed ${ }^{17}$.

Accordingly, there are many strategies to estimate right graft weight and volume (Table 2). In our review, were found at least 11 different $2,3,4,6,7,8,9,11,12,17,18,21,22$, and sometimes conflicting, mathematical formulas aiming to predict graft size. Some of these methods do not use the computed tomography volumetry, but body surface area, and the diameter of the portal vein and/or their branches. This wide variation could be explained by donor's heterogeneity due to age, gender, regional demographics, inclusion or not of the medium hepatic vein in the graft, different types of preservation solution, among others. The main purpose of our study was to determine the correlation between EGV and AGW in our center. We found that $1.00 \mathrm{ml}$ of preoperative CTV correlates with $0.82 \mathrm{~g}$ of graft weight. Then, we believe that use the coefficient of 0.82 can predict more accurately the right hepatic graft weight in our population.

\section{CONCLUSION}

The one-to-one rule did not apply in patients with normal liver parenchyma. A better estimation of graft weight could be reached by multiplying estimated graft volume by 0.82 .

\section{REFERENCES}

1. Ben-Haim M, Emre S, Fishbein TM, et al. Critical graft size in adult-toadult living donor liver transplantation: impact of the recipient's disease. Liver Transpl 2001;7:948-953.

2. Chan SC, Liu CL, Lo CM, et al. Estimating liver weight of adults by body weight and gender. World J Gastroenterol. 2006 Apr 14;12(14):2217-22.

3. Chan SC, Lo CM, Chok KS,et al.Validation of graft and standard liver size predictions in right liver living donor liver transplantation. Hepatol Int. 2011 Mar 26.

4. Gondolesi GE, Yoshizumi T, Bodian C, et al. Accurate method for clinical assessmentofrightlobeliverweightinadultliving-related livertransplant. Transplant Proc. 2004 Jun;36(5):1429-33.

5. HiroshigeS, Shimada M, HaradaN, etal.Accurate preoperativeestimation of livergraft volumetry using three-dimensional computed tomography. Transplantation. 2003;75:1561-4.

6. Hwang S, Lee SG, Kim KH, et al. Correlation of blood-free graft weight and volumetric graft volume by an analysis of blood content in living donor liver grafts. Transplant Proc. 2002 Dec;34(8):3293-4.

7. Kayashima $\mathrm{H}$, Taketomi $\mathrm{A}$, Yonemura $\mathrm{Y}$, et al. Accuracy of an age-adjusted formula in assessing the graft volume in living donor liver transplantation. Liver Transpl 2008; 14:1366-1371.

8. Khalaf H, Shoukri M, Al-Kadhi Y, et al. Accurate method for preoperative estimation of the right graft volume in adult-to-adult living donor liver transplantation. Transplant Proc. 2007 Jun;39(5):1491-5.

9. Kim KW, Lee J, Lee $H$, et al.Right lobe estimated blood-free weight for living donor liver transplantation: accuracy of automated blood-free CT volumetry--preliminary results. Radiology. 2010 Aug;256(2):433-40.

10. KiuchiT, Kasahara M,UryuharaK, etal.Impactofgraftsizemismatchingon graftprognosisinlivertransplantationfrom living donors. Transplantation 1999;67:321-7. 
11. Lee WC, Lee CS, Soong RS, et al. Split liver transplantation in adults: preoperative estimation of the weight of right and left hemiliver grafts. Liver Transpl. 2011 Jan;17(1):93-4.

12. Lemke AJ, Brinkmann MJ, Schott T, et al. Living donor right liver lobes: preoperative CT volumetricmeasurementforcalculation of intraoperative weight and volume. Radiology. 2006 Sep;240(3):736-42.

13. Ogura Y, Hori T, El Moghazy W, et al: Portal pressure $15 \mathrm{mmHg}$ is a key for the successful adult living donor liver transplantation utilizing smaller grafts than before. Liver Transpl 16:718, 2010

14. Radtke A, Nadalin S, Sgourakis G, et al. Liver "compliance": a previously unrecognized preoperative predictor ofsmall-for-size syndromein adult living donorlivertransplantation. TransplantProc.2008Nov;40(9):3142-6.

15. Raia S, Nery JR, Mies S.Liver transplantation from live donors. Lancet. 1989 Aug 26;2(8661):497.

16. Salvalaggio PR, Baker TB, Koffron AJ, et al.Liver graft volume estimation in 100 living donors: measure twice, cut once. Transplantation. $2005 \mathrm{Nov}$ 15;80(9):1181-5.
17. Satou S, Sugawara Y, Tamura S, et al. Discrepancy between estimated and actual weight of partial liver graft from living donors. J Hepatobiliary Pancreat Sci. 2011 Jul;18(4):586-91.

18. Tongyoo A, PomfretEA, PomposelliJ.Accurateestimation of living donor right hemi-liver volume from portal vein diameter measurement and standard livervolume calculation. Am JTransplant.2012 May;12(5):122939.

19. Troisi $R$, de Hemptinne $B$ Clinical relevance of adapting portal vein flow in living donor liver transplantation in adult patients. Liver Transpl. 2003 Sep;9(9):S36-41.

20. Van Thiel DH, Hagler NG, Schade RR, et al. In vivo hepatic volume determination using sonographyand computed tomography. Validation and a comparison of the two techniques. Gastroenterology. 1985 Jun;88(6):1812-7.

21. Wang F, Pan KT, Chu SY, et al. Preoperative estimation of the liver graft weight in adult rightlobe living donor liver transplantation using maximal portal vein diameters. Liver Transpl. 2011 Apr;17(4):373-80. 